\title{
"I can actually be very feminine here": contradiction and hybridity in becoming a female mathematician
}

\author{
Solomon, Y., Radovic, D., \& Black, L.
}

\begin{abstract}
A common theme in accounts of choosing mathematics is that of persistence in the face of troubles or difficulties which are often associated with the structuring effects of gender, class, culture and ethnicity. Centring on an analysis of one woman's account of becoming a mathematician, we build on our understanding of multiple and developing identities with the aim of capturing the nature of individual challenge to structuring discourses, and its implications for choice and participation in mathematics more generally. Inspecting how she talks about events in past, present and future, we expand on Leont'ev's $(1978,1981)$ notion of leading activity to explore how we organise and prioritise activities (and their related identities) within the context of Holland et al.'s (1998) theory of identity in practice, hybridity and worldmaking. We interrogate the part played by contradiction in creating space for individual agency through its resolution in hybrid practices and its relation to social change, exploring how our informant narrates taking up mathematics 'against the odds' as part of an ongoing process of 're-writing' herself into new imagined worlds. In providing an insight into how one individual envisages and enacts a different mathematics culture in which she can have a place, our analysis suggests ways forward in creating new, more inclusive, mathematics education.
\end{abstract}

\section{Keywords}

Gender, Contradiction, Hybridity, Leading Identity

\section{Introduction: The problem of participation}

Although in recent years women have started to show equal or even better achievement than men in mathematics, their participation in post-compulsory mathematics and mathematicsrelated areas remains lower. For instance, in 2013, girls in England and Wales, where this study took place, performed as well as boys in mathematics in the General Certificate of Secondary Education (GCSE) public examinations at the end of compulsory schooling at age 16 , with the exception of the top A* grade attained by $5.2 \%$ of boys compared to $4.7 \%$ of girls (DfE, 2013), but they made up only $40 \%$ of entrants for Advanced Level Mathematics examinations at the age of 18 , and just $30 \%$ of entrants for the more 'select' Further Mathematics Advanced Level (Joint Council for Qualifications, 2013). In UK Higher Education, female representation also drops in the move from undergraduate to postgraduate studies (in mathematics from $43 \%$ to $35 \%$ ), with only $6 \%$ of professors in mathematics in the UK being female (London Mathematical Society, 2013). In the mathematically demanding general area of STEM (Science, Technology, Engineering and Mathematics), only 13\% of all STEM jobs in the UK are occupied by women (WISE, 2012). 
In theorizing about the reasons for this underrepresentation, different authors have suggested an apparent lack of discursive spaces in which to be a 'mathematical woman'. For example, Mendick (2005) suggests that a good/bad mathematician opposition works in parallel with the binary opposition between male/female with the consequence that girls and women who are good at mathematics see their femininity compromised. Identity work is required in order to make apparently contradictory selves 'fit', therefore; this is something that is difficult to achieve. Thus Walls (2009) and Rodd and Bartholomew (2006) suggested that girls and women who do mathematics cope by becoming 'invisible', while other theorists focus on an uneasy sense of belonging (Hall, 2010; Solomon, 2007) or a gender 'division' in mathematics itself (Mendick, Moreau \& Hollingworth, 2008). The focus on identities which is common to these and other studies builds on another body of research which explores patterns of interaction in mathematics classroom contexts and the discursive context of mathematics in our society more generally. Such research identifies structuring practices and discourses which position girls and women in particular ways; thus Black (2004 a, b), Boaler (2002) and Boaler and Greeno (2000) emphasise the connection between traditional 'transmission' classroom practices as potentially excluding of girls, while Forgasz, Becker, Lee and Steinthorsdottir's (2010) and Forgasz and Rivera's (2012) edited collections extend the issues to social structures of gender and participation more generally.

Our concern in this paper is with the connection between individual identity in doing mathematics and the social structuring discourses of gender and participation. We approach this issue through an exploration of the nature of agency defined here in terms of one woman's refusal to be solely determined by macro-level structures which may position her as outside of mathematics. As such, we are interested in how individuals are able to negotiate the contradictions which are inherent within the social structure whereby the commodification of mathematics is situated in opposition to the social value ascribed to certain cultural positions, including femininity.

\section{Agency and identity in doing mathematics}

A common theme in our previous work (Black \& Williams, 2013; Black, Williams, Hernandez-Martines, Davis \& Wake, 2010; Solomon, 2012) has been to look at students who have encountered troubles or difficulties in relation to mathematics but who have persisted with it anyway. Our theoretical perspectives have offered explanations which are fundamentally linked to notions of agency, change and development. Building on Leont'ev (1981), Black et al. (2010) and Black and Williams (2013) suggest that the 'energy' to persist with mathematics may be manifest in a specific 'leading identity' which enables the individual to 'see' mathematics activity as relevant to their adult life beyond the school walls or to their social life beyond mathematics. Following Bakhtin $(1981,1986)$ and Holland, Lachicotte, Skinner and Cain (1998), Solomon (2012) looks at the issue of agency in choosing mathematics in terms of the orchestration of contradictory discourses in a constant process of becoming. In employing these theoretical positions, we have been interested in change on two levels: for the individual, in terms of their developing sense of who they are in 
relation to mathematics; and for society, in terms of how individual reflexivity contributes to transformation of mathematics education practice.

In this paper we take this analysis further, elaborating on the connection between Leont'ev's and Holland et al.'s theoretical approaches to understand one woman's account of her individual trajectory in mathematics within a personal history of structures which discourage her participation. Specifically, we pick up the story of Roz, begun in Solomon (2012), and elaborate on her subsequent development as a female mathematician. By building theory on an exploration of the nature of, and relationships between, contradiction and hybridity in the development of the self, we explore how her response to past and current struggle is resourced by a particular leading identity (becoming a professor of mathematics). In doing so, we frame some answers to questions about individual agency and individual and social change. How might those who do not or cannot participate in mathematics come to see themselves as doing so? What implications does this have for wider social change?

\section{Theorising development of the self}

\section{Multiple identities}

Our use of both Holland et al. (1998) and Leont'ev (1981) has emphasised that identity is not a unitary concept but is multiple in nature (identities rather than identity), and, importantly, is always in the process of becoming, being derived from the "figured worlds' with over the course of our lives. Hence,

Because the self is the nexus of a continuing flow of activity and is participating in this activity, it cannot be finalized. It cannot step outside of activity as "itself"; the self as it reflects upon its activity is different from the self that acts. ... The self authors itself, and is thus made knowable, in the words of others (Holland et al., p. $173)$.

Along similar lines, multiple identities can be related, in Leont'ev's $(1978,1981)$ terms, to the multiple motives and subjectivities we encounter through engagement in the vast array of activities throughout our lives. However, for Leont'ev (1978, Chapter 5), such multiple subjectivities and activities are not completely unrelated but are brought together in consciousness through what he calls 'personality', which prioritises certain activities as 'leading' on the basis that they are more developmentally significant than others. In this respect, certain activities can be said to pave the way for psychic development because they offer a motive which prepares for the next phase of activity as defined by the social structure (e.g., pre-school kindergarten to formal schooling, school to work, etc.):

\footnotetext{
${ }^{1}$ A figured world is 'a socially and culturally constructed realm of interpretation in which particular characters and actors are recognized, significance is assigned to certain acts, and particular outcomes are valued over others' (Holland et al., 1998, p.52)
} 
We mean by [leading activity] not simply the activity that is most often encountered at a given level of a child's development (...) We call leading activity that in connection with whose development the most important changes take place in the child's psyche and within which psychic processes develop that pave the way for the child's transition to a new, higher level of development (Leont'ev, 1981, p.4).

Here, Leont'ev discusses the pre-schooler's engagement in rule-based play as leading them towards the next phase of instruction and formal schooling. What this then provides is a notion of development or 'telos' in our understanding of how we organise and negotiate our multiple identities. As we have argued elsewhere (Black \& Williams, 2013; Black et al., 2010), the self/personality is not fragmented but structured and shaped by those identities that are 'leading' developmentally, and this 'leading identity' can be said to provide a hierarchical structure to the process of organising one's personality.

While Holland et al. (1998) do not include such an emphasis on telos, they incorporate a sense of direction in development in their use of Bakhtin's account of the heteroglossic nature of self which, they suggest, inevitably involves taking an authorial stance. Bakhtin expresses this as the need to make a choice:

Consciousness finds itself inevitably facing the necessity of having to choose a language. With each literary-verbal performance, consciousness must actively orient itself amidst heteroglossia, it must move in and occupy a position for itself within it, it chooses, in other words, a 'language' (Bakhtin, 1981, p. 295).

The synergy between these theories lies in the way they deal with agency, consciousness and choice - our notion of leading identity suggests prioritisation of one (or more) identity(ies) over others through reflection - this is where agency lies. Similarly, Holland et al. (1998, p. $170 \mathrm{ff}$.) focus on consciousness of choice as something which must be done; in choosing we exercise agency in authoring the self.

\section{Reflections, contradictions and leading identity}

The notion of identity in use here is not merely discursive (or narrative) but it is mediated by practice. We take the position along with Holland et al. (1998, Chapter 13) that people cannot simply decide to adopt an identity discursively; it needs to be acted out through engagement in activity which entails performance and recognition by others. Organising oneself in the name of an identity develops as one encounters cultural artefacts as part of an ongoing practice with others and then at some point applies the cultural resource to oneself. In our previous work we have argued that the business of organising and structuring identities within or through personality involves a special kind of 'identity-in-practice' - one that is made visible in particular kinds of discursive spaces (like the research interview) (Black et al., 2010). This inherently involves reflection and self-regulation which Holland and Lachicotte (2007) suggest can be classed a 'higher order psychological function' in Vygotskian terms. To relate this back to our account of Leont'ev's leading activity, we might suggest that the shifting motive of the 'leading' activity brings about a new subjectivity and 
through reflection this becomes an identity to which we orientate or 'imagine' ourselves to be. Furthermore, through ongoing reflection and self-regulation we structure (or 'orchestrate') the personality around that which is developmentally significant.

Contradictions are significant here as a major driver of development and change in Vygotsky and Leont'ev's work (see for example Leont'ev, 1978; Vygotsky, 1978) since this provides the capability to transcend present situated activity and create a new activity through semiotic regulation of one another and oneself. For instance, in the case of a child pretending to ride a horse using a stick, Vygotsky (1978, p.99) tells us that play is the resolution of a contradiction between the child's need to engage with the adult's motive (horseriding) and their limited resources/capability to do so. Through play the child can 'imagine' what it is like to ride a horse and be like an adult and thus, temporarily at least, resolve the contradiction.

This resonates with Holland et al.'s (1998, p.273 ff.) account of improvisation which they suggest takes place when an individual experiences a certain combination of circumstances and conditions for which they have 'no set response'. Their example of the Nepalese woman who climbs up the outside of a house in order to participate in a research interview can be viewed as an impromptu response to a contradiction between her desire to participate in the 'upstairs' interview and her position as a lower caste member who cannot cross the threshold of a higher caste family. Holland et al. (1998) view such improvisations as openings for change and development:

Improvisations are the sort of impromptu actions that occur when our past, brought to the present as habitus, meets with a particular combination of circumstances and conditions for which we have no set response. Such improvisations are the openings by which change comes about from generation to generation .... The improvisations of the parental generation are the beginning of a new habitus for the next generation ... Improvisations... are, when taken up as symbol, potential beginnings of an altered subjectivity, an altered identity. (Holland et al., 1998, pp.17-18)

However, in the context of major structural (re)positionings, a single realisation, while it clearly has the potential to lead to change, can only be the beginning of an ongoing process of confronting contradiction, and an ongoing desire to do so. So to take another example from Holland et al.'s work in Nepal, focusing on the Tij festival as a site for potential change 'world-making' - in the situation of women in Nepalese society, we would argue that, in addition to imagining a more egalitarian world through songs, the Tij women would have to persist in meeting the contradictions of their position over time and in the community outside of the festival for change to happen - songs are not enough.

Extending Holland et al. (1998), therefore, we suggest that we need an account of how individuals are propelled to consistently resolve contradictions over time. We believe our notion of leading identity may be helpful here, since it recognises that individuals act (in the context of joint activity) in relation to a particular organisation of the self which gives 
meaning to different types of activity - with some given priority over others. Where an activity is prioritised (both socially and individually) through the process of organising the self, we are likely to improvise, pursuing new possibilities as a means of negotiating the contradictions we encounter and in so doing engage with new goals which further 'lead' development.

\section{Hybridity and worldmaking}

Contradictions provide an important source (or resource) for agency since dealing with such conflict involves some kind of 'hybridisation' where old and new (or past and present) come together. In our previous paper on Roz (Solomon, 2012), we focused on a highly contradictory narrative in terms of aspirations towards a feminist stance which were compromised by her take-up of the 'authoritative discourse' of the 'male brain'. We highlighted a struggle to 'hybridise' these conflicting accounts as indicative of a potential to imagine new worlds. This situates such contradictions not only within the wider social structure, but in a chronology whereby history (identities from the past) and those identities emerging in the present, come into contact. In the process of self-authoring, Roz retained memories of her former experience of a collaborative mathematics and the possibilities for a different future for herself. This analysis reminds us of Holland et al.'s notion of a 'hard-won standpoint' as part of an ongoing exercise of agency:

Thus persons and, to a lesser extent, groups are caught in the tensions between past histories that have settled in them and the present discourses and images that attract them or somehow impinge upon them. In this continuous self-fashioning, identities are hard-won standpoints that, however dependent upon social support and however vulnerable to change, make at least a modicum of self-direction possible. They are possibilities for mediating agency (Holland et al., 1998, p.4)

This captures for us an idea of identity(ies) as a 'staging post' in a journey of the self. The contradictions evident in Roz's case (Solomon, 2012) may provide a space for agency, where, temporarily at least, new 'hybrid' identities are possible.

As we have suggested, Roz's struggle to hybridise is indicative not just of her own becoming self as a mathematician, but also of a potential to 'figure it otherwise', to imagine new worlds of mathematics. In this paper, we pick up Roz's story as told in an interview two and a half years later, and explore in detail her negotiation of contradictions in becoming a female mathematician, and her enactment of new 'hybrid' mathematical practices in a reimagined world. In doing so, we show how a concept of leading identity adds to our understanding of Roz's story of her becoming as a mathematician against the odds, enabling a particular organisation of the self which prioritises and gives meaning to her activities.

\section{Methods and Data}

Roz returned to university about 8 years ago, undertaking undergraduate, masters and $\mathrm{PhD}$ 
degrees in mathematics. At 52 years old she is now engaged in post-doctoral study at the same highly prestigious university where she undertook her $\mathrm{PhD}$. Initially interviewed at the end of her masters course, she agreed to a further interview 3 years later, providing the data for this paper. The interview, which was fully transcribed, took place in a university cafe, and was loosely structured around our interests in her on-going account of her mathematics career, particularly her account of the past, present and future, and of the impact of being a mother on her career. As focused on in Solomon (2012), we are mindful of the coconstructed nature of the interview, which is even more the case now, given our shared history and our understanding that meeting again in the future is very likely. However, we exploit this fact in our analysis, situating our reading of this interview with Roz in the context of the previous one. Additionally, we see this interview as part of an on-going story-telling which situates Roz's mathematics life in her past and future, describing identities which cross the boundaries between this particular practice and others. In our analysis, we focus on the role of contradictions and hybridity in her account of self, and in particular the part played by gender narratives in her vision of the mathematical world and her place in it. Drawing on the theoretical positions outlined above, we have operationalised key concepts in order to read the data, as described in Table 1.

Table 1: Concepts used to read the data

\begin{tabular}{|l|l|}
\hline Concept & Operationalisation \\
\hline Contradiction & $\begin{array}{l}\text { Following Leont'ev (1978, 1981), we refer to contradictions as } \\
\text { oppositions existing side by side - these do not cancel each other out } \\
\text { but define each others' existence. Furthermore, contradictions are } \\
\text { viewed as part of process of development in that they provide a sense } \\
\text { of crisis which one must resolve in the production of new forms of } \\
\text { activity and identity. We have used contradiction in our analysis to } \\
\text { explore oppositions in our informant's story and to consider how these } \\
\text { form part of her ongoing story of development. }\end{array}$ \\
\hline Motive & $\begin{array}{l}\text { In activity theory, each and every activity contains a motive - a need } \\
\text { that drives a group/collective of individuals to act on/with an object in } \\
\text { the pursuit of a goal/objective - which they may or may not be } \\
\text { conscious of. For Leont'ev (1981), motive mediates the dialectic } \\
\text { relationship between the individual mind and the collective activity } \\
\text { bringing about a specific 'objectivisation of needs'. We identify } \\
\text { 'motive' where the informant discusses her 'need' or reason to } \\
\text { act/engage with an activity and where this need aligns or even } \\
\text { transforms the collective activity (e.g., academia/mathematics). }\end{array}$ \\
\hline
\end{tabular}




\begin{tabular}{|c|c|}
\hline Leading Activity & $\begin{array}{l}\text { This is used to identify an activity that involves a shift in motive for } \\
\text { the individual as told within the narrative e.g., in comparing past } \\
\text { events versus present. What is defined as a leading activity must be } \\
\text { shaped by the social structure as well as the individual - which means } \\
\text { that the activity in question must fit broadly with the typical patterns of } \\
\text { activities one might develop through in a given society (e.g., play- } \\
\text { school-work-retirement - Beach, 2003). Therefore we have identified a } \\
\text { leading activity, as one deemed as developmentally significant for the } \\
\text { individual and by the social structure. }\end{array}$ \\
\hline Leading Identity & $\begin{array}{l}\text { We use this concept to denote the reflected 'subject' of the leading } \\
\text { activity in line with Holland et al.'s (1998) definition of identity. As } \\
\text { we reflect on our engagement in a leading activity we draw on a } \\
\text { socially shared identity of being and becoming a 'person who does x'. } \\
\text { - this reflection involves imagination. Therefore, we identify a leading } \\
\text { identity where the informant refers to being or becoming (I am x, I } \\
\text { would like to be y) an identity which is associated with the leading } \\
\text { activity (defined above). }\end{array}$ \\
\hline Hybridity & $\begin{array}{l}\text { We use hybridity and hybridisation to refer to the production of new } \\
\text { forms of identity as a resolution to a contradiction between two } \\
\text { juxtaposed identities. In our use of hybridisation we are mindful that } \\
\text { the 'old' forms are not lost, they are simultaneously retained and } \\
\text { destroyed in the new form. Drawing on Bakhtin (1981), Holland et al. } \\
\text { describe hybridisation as taking an authorial stance in the orchestration } \\
\text { of multiple voices and, in doing so, "re-figuring the space of } \\
\text { authorship, multiplying the possible ways of identifying activity." } \\
\text { (p.315). This captures the significance of producing hybrid forms not } \\
\text { only in terms of an individual's ontological development but in social } \\
\text { transformation too. }\end{array}$ \\
\hline World Making & $\begin{array}{l}\text { Building on Vygotsky's theorising of play and imagination, a key } \\
\text { concept in Holland et al.'s (1998) is the use of existing cultural } \\
\text { resources to effect change. Thus 'world-making' is the orchestration of } \\
\text { existing discourses to author new ways of being. In this 'serious play', } \\
\text { selves are "assembled from, and in relation to, cultural resources" } \\
\text { (Holland et al., p.289). We identify 'world making' where the } \\
\text { informant uses existing cultural resources - references to popular } \\
\text { culture, to social debates, and to activities which are outside the norm - } \\
\text { to imagine a different social positioning and structure. }\end{array}$ \\
\hline
\end{tabular}


The interview was initially analysed independently by the authors drawing on the concepts in Table 1 in order to interrogate the data, followed by a collaborative analysis to highlight and discuss any differences and similarities between interpretations. Having identified key elements of the data in this way, we moved to a holistic reading which aimed to understand and explore the connections between them, drawing on our theoretical framework developed above. Specifically, we were looking for indications of the role of contradictions in Roz's story and the way in which these produced struggle and hybridity in her enactment of being and becoming a mathematician. In what follows, we present our analysis in these terms, exploring the way in which our focus on the contribution of leading identity enables an understanding of Roz's story of development and world-making.

\section{Analysis}

\section{Producing potential hybridity? Roz's location amidst binary discourses}

We begin here by noting a contradiction in Roz's story in terms of her aspirations towards a feminist stance alongside acquiescence with a discourse that mathematics requires particular cognitive characteristics which are strongly associated with masculinity. In line with this discourse, which for her is legitimised by Simon Baron Cohen's book 'The essential difference', she describes herself as a 'systematiser', citing this as one of the reasons why she chose to pursue a mathematics career:

\section{[... how do you account for that then like in terms of why you ended up in maths} rather than ... I don't know ... something else?] I don't think I'm very good at relationships (...) I read ... what's it called ... Simon Baron-Cohen - The Essential Difference. Made a lot of sense to me ... and I'm definitely a systematiser. And I think that ... well I think an explanation which really satisfies me, which I don't necessarily claim to be absolutely true ... is that I don't pick up the unspoken social cues that generally girls have. So I was always violating some unspoken rule or other, making me unacceptable ... but I didn't even know what that was. And so coming to that conclusion really released me from the angst of why did I never have friends when I was a child.

For Roz, being a 'systematiser' is strongly linked to gender: she reads Baron-Cohen's work as a clear indicator of essential differences between men and women which culminate in a strict binary between the 'male and female brain'. She thus describes the results of the empathising/systematising test that is central to this work (see Baron-Cohen, 2003, pp. 201216) as explaining her perceived inability with relationships as a child: she sees 'femaleness' as being people-oriented, something which conflicts with analytical mathematics skills.

However, this claim to essentialism (articulated near the beginning of the interview) contradicts a more persistent storyline where Roz subscribes to a feminist stance in relation to mathematics, insisting that 'you don't have to give up being female to be a mathematician'. 
We noted in the previous paper (Solomon, 2012) that in her first interview Roz did not appear to be able to sustain this identity, falling back into an explicit 'male brain' discourse; but now, she reflects on this contradiction and theorises further about the issues to develop her ideas about making her femininity visible, in contrast to the majority of women in mathematics:

I think women are generally accepted in Mathematics as you know ... you know they can be good mathematicians too ... but I think the ones that are, tend to be very frumpy in their dress, they tend to be very masculine in their dress. It's almost as if they're still trying to hide their gender.... So one professor ... if she's wearing trousers you would mistake her for a man from behind ... And even the young ... there's a young lady, and she's absolutely delightful, but you know she wears ... she wears glasses and not contacts, she puts her hair in a ponytail, no make-up, always sort of jeans and a top ... not a particularly feminine top, just a regular T-shirt. And she goes ... she even walks in a kind of butch way somehow. And um ... you know I don't sort of in any way disrespect her choices, but I just think well maybe she feels the need to do that, either consciously or otherwise.

One might argue here that Roz subscribes to the idea that femininity and mathematics are opposites - they don't typically co-exist and are hence contradictory. For women to be accepted in mathematics they cannot be the 'other' of the 'male brain' discourse but must somehow align with it. But Roz is determined to steer a different course:

I thought ... you know there's a part of me that wants to be dressed like a proper woman as well, but there's also this kind of thing going on that actually you know I want to show that I can be a proper woman and I can dress ... I could wear heels and I can wear a skirt and dresses.

Here we can see that whilst Roz views the other women as having resolved the contradiction between being female and being a mathematician by taking on masculine characteristics in order to fit into the world of mathematics, she has chosen to be different - to enact a different kind of mathematical identity, which retains simultaneously a strong and visible femininity (signalled by the use of the cultural tools of skirt and heels) alongside the mathematics. It is in this sense, we suggest, that Roz is in the process of producing a new hybridised identity out of the contradiction she has experienced and observed. In what follows, we will argue that this contradiction between doing mathematics and enacting femininity is not resolved by her 'loss' of one of these activities over the other; rather, both are retained in the production of what she perceives to be a new way of being a mathematical person.

\section{Struggle and fragility in enacting hybridity}

As our theoretical framework suggests, negotiating contradictions and the production of hybridised identities involves struggle in order to attain a 'hard won standpoint', and Roz's 
story is one of constant struggle. She stories her current identity as a successful postdoctoral mathematician as nevertheless fairly fragile; she has battled to get to this point, moving from her 'late start' at a less prestigious university to her current one, but she consistently describes potential failure as always just around the corner:

And I feel like I'm clinging on to the edge - I'm not going to let go now. ...in spite of what my boss always said, I still feel insecure about my ability to do maths, you know. And they do say some quite disparaging things, not all of which are true, about [her undergraduate] University round here, so ... I kind of worry I think that the current project is going to reveal things I don't know, that they would normally expect an undergraduate to have done, but that weren't available at [her undergraduate University]. You know like the theoretical algebra stuff.

While fear of 'being found out' is a familiar theme in many mathematicians' stories, in Roz's story this emerges as a current point of tension and survival which is preceded by a string of small victories in which she has overcome difficulties in an environment which is unwelcoming in terms of her particular life choices - to be a stay at home mother when her children were small, and to study as a mature student at a local university once they were older. She has encountered overt prejudice based on assumptions about the quality of her undergraduate degree, the most recent incidence of her on-going struggle. But she repeats a now familiar theme of not giving up, in spite of the difficulties:

Just after I got my offer from [postgraduate University] to do the Masters and $\mathrm{PhD}$ here, he said 'Congratulations ... you're not [postgraduate University] material, you won't be heard, don't go and embarrass us in public'. .... Yeah so I mean my attitude has always been they're probably right, but I'd rather try and fail than not try. Cos I just feel like I want to do this.

As such, triumph over adversity is important to her, and this, essentially, is the story of her life:

[... if somebody was making a movie about you, about your life ... What's the movie trailer going to say?] Well ... for a movie, you need some conflicts, right, you need some conflicts to get people engaged, you've got to think 'How did that happen?' right. So you have to whet the appetite cos people are not going to watch a real movie about a real life which is to do with scrubbing toilets and washing up, you know helping children with their homework and doing all the worthy things that really need to be done ... so it would have to be something like 'They all said she couldn't do it, she triumphed at last'...

Although our question clearly invites a response which draws on familiar popular culture genres of overcoming adversity, what is important here is Roz's choice to connect the story of becoming a mathematician 'against the odds', articulated throughout the interview, to her gendered past and the domestic role that this entailed. She vehemently defends her past decision to be a stay at home mother (unlike her own mother) for 20 years, taking what she 
believes was the only 'right' course of action. For Roz, this is part of the perceived contradiction between being female and being a mathematician (this time located in her past rather than the present) but it is one that she sees herself as overcoming - 'she triumphed at last'. In the next quote she articulates this even more clearly in terms of her departure from the norm:

... thinking about writing a press release for my local paper when I have my graduation and things like that you know. This is going to be the human interest side of it, isn't it, you know 'Local mum makes good' kind of thing 'Local mum ...' you know ... I'm a woman, I'm a mum, I'm middle aged, I've gone to university and all that side of things .. you know I've done a lot of things out of the normal sequence. So you know ... that's the real interest .. for other people that's the interest.

Significantly, Roz describes her pathway into and through mathematics in terms of the resolution of contradictions around femininity and an on-going gender issue in which retaining her femininity alongside being a mathematician is key to who she is. She thus enacts a hybridised identity which emerges out of the contradiction arising from her engagement in an activity which she perceives to be essentially masculine.

Furthermore, such contradictions (and Roz's subsequent hybridising) are not merely part of a narrative; they are firmly rooted in the social structure where traditional gender roles (motherhood, domesticity) conflict with the male mathematics identity that Roz sees as prevalent in academia. We suggest, then, that Roz expresses a 'hard won standpoint' as she tells of her accumulated victories in negotiating such contradictions; we argue next that her storying of her own history in person further resources her production of a different and new form of mathematical identity where motherhood, maturity and mathematics combine.

\section{The role of Leading Identity in enacting hybridity}

Roz's story of struggle is characterised not only by a narrative of overcoming contradictions but also by a strong desire to continue and succeed in mathematics despite what others say, expressed here in another imagined account of how her life story might be represented in popular culture:

[What about for you, is that what you would like to be the headline [for a newspaper story about her]?] Does it matter? I mean you know what does it matter what other people think? ..... because I didn't take their word for it, did I? ... I wanted to do it. And the opportunity came and I wanted to ... why would I let something like that stop me, you know. Why would I ... yes, they may be right, and I feel deeply that they may be right ... but I'm going to have a go. ... ... maybe I was going to fail the Masters. And okay they'd be embarrassed of me, and that would be hard to bear, but ... you know they might have been wrong. Probably they were. ... I just feel really strongly that I want to do this. ... "Feel the fear and do it anyway" - that can be the 
movie title. ... Yes, and then the trailer is you know 'They said she couldn't do it, they stood in her way. But there it is, she overcame!'

While overcoming contradictions has led Roz to enact a new hybridity as she lives out her identity as a mathematical woman, this is, clearly, a site of struggle for her. While contradictions appear to spur her on - she wants to 'prove them wrong' - sustaining hybridity also requires a vision of the future. Roz describes this imagined future as a career in academia which she intends to pursue despite the perceived difficulty of doing so:

Because not everybody with a $\mathrm{PhD}$ gets to professor. And being somebody who was a late entrant, who's been repeatedly told they can't do it, you know ... it would be kind of nice. .[..]And realistically if I'm going to be a professor, I need to be a professor in 10 years, which means I need something in the region of ... is it 2000 citations? [..] 2000 citations, a grant income of $£ 100,000$ a year - that sort of thing. [..] And lots of papers. Lots of papers. [...] I've three out of my PhD....but I've not had a rejection yet. (laughs)

The past is also part of Roz's story of her strong engagement with mathematics. She talks about her early love of physics and the influence of her father's job as an engineer, claiming a 'genetic predisposition' to do mathematics inherited (perhaps significantly from a gender point of view) from him, which also appears to propel her to an imagined future of 'professorial success against the odds'. Wanting to do mathematics was and still is a major driver in her life:

Always loved Physics mind you - absolutely adored Physics. My father was an engineer so ... And when we were tiny he would bring home the scrap paper with all the technical drawings on for us to use the other side of .. . I was just fascinated with the drawings themselves, and the precision with which they designed even the (inaudible) in the lid, and how things worked - I just loved it. And I was just gazing at these and how things worked and whatever ... so it was always in there I think. .... I mean part of it's intrinsic isn't it, genetic - I'm much more like my father than my mother. So the things that he liked - I like. [...] So I think it was already in there to a large degree.

We argue, then, that doing 'academic mathematics' has become a leading activity for Roz her motive for engaging with this activity has developed from an 'intrinsic love' of the subject (which still remains) towards one more aligned with academia - meritocratically (career progression, publishing papers) and altruistically (more on this below). For Roz, this shift is developmental - it has moved her along a particular telos towards a leading identity (becoming a professor). Her current leading activity (academia/research in mathematics) is therefore not only resourced by the struggles which emerge from the contradiction of being a woman and loving mathematics but it also enables her to pursue a different or 'new' identity 
when compared to others (recall Roz's account of the more typical women she sees in mathematics who are, she says, not particularly feminine). Like the aforementioned preschool child who, through play, negotiates the contradiction of wanting to 'become' adult but not having the resources to do so, Roz finds in academia an imagined space which is resourced by - but also continues to resource - her motive for engaging with mathematics.

\section{World-making: a hybridised practice of mathematics}

We are concerned in this paper with the connection between individual development and the social structures which, in Roz's case, create conditions in which it is difficult to choose mathematics. We have argued that the very struggle which she has encountered in producing a new hybrid identity is a resource for Roz in her choice of mathematics and her continued development as a female mathematician. Part of this development involves her engagement in new activities which we can see as world-making: these are indicative of change on an individual level, but they also contribute to (and are simultaneously enabled by) change in the mathematics context itself. On the individual level, Roz sees herself as not particularly 'good at relationships', and indeed she said this in her previous interview, but in her current role she feels she can exercise this feminine characteristic, as she sees it, in the context of the maledominated mathematics department:

... I tend to become a bit of a hub now ... and I'm the person who cares about the fact that there should be cohesion in the department and relationships should be built, and the new person should feel welcome ... even though I wasn't ... and all this kind of stuff. So I think (inaudible) I found my niche. Because in a more empathetic setting, I would probably be the person who would be behind on those things. But in a sort of setting like this, where people ... this kind of thing tends to pass a lot of people by altogether, and some people just don't know how to do it and haven't got any confidence ... I can then flourish. And I can do ... I can actually be very feminine here.

This exercise of the feminine within departmental relationships, as she sees it, also extends to the use of mathematics to help people. This is an issue originally raised in the first interview, harking back to her attendance at a pre-university master class ('for the first time ever I realised maths could make people's lives better. ... maths can describe the world and make it a better place for people, [it] just completely blew me away - and that's really where it started'). She picks this theme up again now, in the context of her worries about being 'found out' about her lack of experience with 'the theoretical stuff', enthusing confidently about how she uses mathematics to help people, and how she enjoys the 'people element' in her current project:

[Is it important to you what you're doing with Maths?] Yeah so ... with the $\mathrm{PhD}$, one of the things I was doing is comparing statistical mathematics and machine learning for tailoring treatments to patients. ... So this is sort of making people's lives better, 
right. If you can go to the doctor and have not the cheapest treatment and hopefully you won't come back, but actually the one that's most likely to work for you ... so this is the motivation behind what I was investigating. And now it's ... networks for food security decision support. So I'm helping ... I will be helping both people who are suffering a food crisis, and also the decision makers who have to then gather all the domain knowledge together in order to make a strategy. So again there's a very strong people element. And we're working with people from Politics, people from Social Sciences, people from Life Sciences as well - crops and so on. So again very multidisciplinary, very practical, down to earth. ... [So is that important to you then about ...] The people element? ...Well I guess I would take ... I would take a theoretical job rather than be unemployed, but yes it is essentially yeah. I mean the whole ... I get up and I love coming in to work - it's because of the people element.

Roz's goal of reaching the highest possible academic status is thus hybridised with her aim for femininity (i.e., 'I can actually be very feminine here'), in a changing world which is partly of her own making. Roz's story is not just about herself but also about how overcoming contradiction impacts and changes the social structures which created the contradiction in the first place - it is an account of world making. This is further evident when she reflects on how the timing of her particular entry into academia has given her an opportunity to be different from other women in mathematics, who have had to fight for their place in mathematics in an earlier world when things were tougher. Here Roz suggests that had she started at the same time, she would have become like the more 'masculine' women in the department or, significantly, would have dropped out. But things have 'moved on', and she is part of that movement, and more able to be the kind of person that she wants to be in mathematics:

... the women I've met here who are a similar age to me, they tend to be quite aggressive. And I think that if I'd gone into maths at that [earlier] age I'd have had either very sharp elbows or I'd have crashed out. But I don't want to become like that $\ldots$ and I recognise that they're only responding to their environment, but I think the world's moved on a bit ... I'm hoping it has anyway ... and I hope that I can ... you know I can be gentle and (inaudible) as well. That's what I'm hoping for, and I think maybe the self-conscious - making sure that I dress like I would if I was an office receptionist or something like that is part of wanting to be like that, wanting to be ... [So what happens to you in the future? Where do you want to be? ] In ten years I want to be applying for a professorship.

We suggest then that in resolving successive contradictions Roz draws on her past, present and future in a way which enables world-making through the enactment of a hybridised practice of being both female and a mathematician. Here, we stress that this does not entail the production of a 'feminised mathematics' - i.e., a 'caring' mathematics which is essentialized as suitable for women, but rather we see here a sublation of gender and mathematics where the old contradiction is preserved in the new, more developed practice. 
Thus Roz enacts her femininity around her mathematics activity in various ways, preserving the (male, according to her) mathematics while carving out an interface with it, which calls on classically feminine characteristics of caring and helping others. This requires creating new spaces within the department and academia more generally, and her use of mathematics itself.

Furthermore, we suggest that Roz's desire to enact a 'feminine mathematician' and the importance of the application of mathematics for making a better world is an integral part of her leading activity, critical to her motive in envisaging a changing world and her own career trajectory. Echoing her earlier claim that in a male-dominated department she stands out as having feminine empathy, Roz feels that she is 'in a place where people think that my social skills are valuable, and uh .. I keep getting invited to do things because I am who I am ... and this is very nice'; she says how much she has enjoyed starting a young researchers' group emphasising public engagement, creating a social life in the department, and starting a 'bakeoff' competition tradition which she is pleased to find goes on without her:

And it survived my departure - this year was the first year I wasn't there to do it ... and they did it still. [So you want to leave a legacy?] Well I'm not conscious of calling it that, but you know ... I want to start things that I think are good. I don't want to leave a legacy for legacy's sake, but I like to change things for the better...

What is critical here is that this 'world making' is not just narrated but is lived in practice through Roz's and others' actions. Without those actions the practice itself cannot change, but at the same time - as Roz realises - she cannot be what she wants to be without wider structural change. So returning to the theme of gender and mathematics, she recognises that being a feminine mathematician (i.e., doing hybridity) is not simply a resolution of old contradictions but also entails confronting new struggles - the battle is not yet won:

I think the next battleground is to be seen as a competent mathematician and a proper lady at the same time. ... I want to assert my right to dress like a woman and still be taken seriously as a mathematician ...

\section{Discussion: contradiction, hybridity and change}

We set ourselves the task in this paper of addressing two questions: "How might those who do not or cannot participate in mathematics come to see themselves as doing so?" and "What implications does this have for wider social change?” By analysing Roz's story we have argued that surviving 'against the odds' in mathematics involves negotiating the contradiction of being a female in a 'male' mathematics world by enacting a new, hybridised way of being a female mathematician. Furthermore, we have argued that this hybridisation is not without its own struggles; its enactment is both resourced by and has propelled her towards an imagined leading identity of becoming one of the $6 \%$ of female mathematics professors in the UK (London Mathematical Society, 2013). 
Part of Roz's enactment of a new hybridity involves world-making as she talks about her contribution to a changing, more socially engaged, world of mathematics. This new identity is produced out of the contradiction of being female/feminine and doing 'male' mathematics through a process of sublation in which the old contradiction is both retained and lost in a new enactment of self which includes the serious play of an imagined future as a professor. For Roz this is a leading identity because it emerges from her current leading activity of doing academic mathematics but also because it offers telos - a sense of progress in her becoming. In enacting this new hybrid identity, Roz is not only surviving 'against the odds' but is also world-making as she creates the possibility for change not just for herself but also for wider community of mathematics.

The theoretical perspectives used here have allowed us to gain a new understanding of contradiction, change and identity in practice. Following Holland et.al's (1998) lead, we see the self as 'the nexus of a continuing flow of activity' (p.173), but here we have focused in particular on the role of contradiction as a resource or source of change and development in the course of that flow. In doing so, we have extended their account of development, which emphasises realisation and recognition of the social structure as important for agency (p.141) and the role of imagination as a source of change. Here, we have explored this process in more depth, in two ways: firstly, in terms of the nature of contradictions which are consistently (re)produced, potentially prolonged and can be painful, as they are for Roz and women like her; and secondly, in terms of the implications of Leont'ev's concept of a leading activity for a sense of telos in the becoming self. Thus in coming to see and hybridise the contradictions between enactments of mathematics and of femininity, Roz does not simply imagine a new future for herself as a professor of mathematics; in becoming she must live with the ongoing struggle that this entails - the contradictions persist in the wider social structure, perpetually throwing up new contradictions for her, and her enactment of a hybridised identity is difficult and real.

Elsewhere we have suggested (along with others) the importance of 'third spaces' where new hybrid activities are possible (Black \& Williams, 2013; Guttierez, 2008; Guttierez et al., 1999); such spaces arise out of wider contradictions between activity systems and structures which make change possible. For instance, we might argue that the need to recruit women into disciplines such as mathematics arises out of contradiction between an economic need for skilled individuals in STEM and insufficient numbers of male adults who have such skills. Recall that Roz speaks of how her feminized mathematics identity would not have been possible twenty years before. We suggest that it is in such structural contradictions that hybridity and worldmaking becomes possible: her reflection raises the motive of the activity to consciousness, and Roz has a clear vision of where she's going now.

\section{Conclusion}

In conclusion, we return to our opening concern with the problem of participation, and 
consider the implications of our analysis for mathematics education. Although, as we have noted above, many researchers have explored the difficulties of women in the mathematics world and have conceptualized these difficulties as contradictions between women's becoming and the structuring effects of gender, most of them have understood these contradictions as hindrances and not as affordances. Our analysis suggests the opposite, providing some insights into how we may foster change. Identity remains central to the issue, but our analysis suggests a stronger role for practice. While a number of writers (e.g., Becker, 1995; Kaiser \& Rogers, 1995) have suggested changes in practice towards more 'girl-friendly' mathematics, our analysis does not lead to this conclusion. On the contrary, we hold on to the implications of Roz's enactment of a hybridised female/feminine mathematician identity in ways which do not attempt to change towards a 'feminised mathematics' or a 'mathematised (masculinised) woman' but, rather, enable recognition of and reflection on such contradictions. This demands a critical approach to mathematics education such as that advocated by Skovmose and Greer (2012) and Gutiérrez and Gutierrez (2013), which enables individuals to 'see' how mathematics is situated within the social structure and how it might be different. As Apple (2012) argues, this involves recognising the contradictions created by the commodification of knowledge (e.g., masculine mathematics as compulsory for all) and illuminating the spaces for action to legitimate and establish alternative and transformative ways of engaging with mathematics education and what it signifies. In practice, this transformative action involves creating educational spaces to enact struggle against dominant ways of being and knowing yet simultaneously using such 'official knowledge' to transform the status quo and make a difference (Gutstein 2006). Pais (2014, p. 1086) has recently stated that "the problem of equity is not exclusive to people who are positioned as being in disadvantage due to their association to some category (ethnicity, gender, linguistic, socioeconomical, etc.)" but is, rather, "a generalised problem of the school system [education], that affects everyone by the way schooling is involved in social stratification". We suggest that Roz's particular enactment of a female mathematician, within the privileged space of mathematics itself, can be seen as part of what Apple describes as on the ground action which is fundamental to transforming the broader social structures which define the value of mathematics in terms of the place it occupies in society. 


\section{References}

Apple, M.W. (2012). Can education change society? New York, NY: Routledge.

Bakhtin, M. (1981). The dialogic imagination: Four essays by M.M. Bakhtin (C. Emerson \& M. Holquist,Trans.). Austin: University of Texas Press.

Bakhtin, M. (1986). Speech genres and other late essays (V. W. McGee, Trans.). Austin: University of Texas Press.

Baron-Cohen, S. (2003). The essential difference. New York: Basic Books.

Beach, K. (2003) Consequential Transitions: A Developmental View of Knowledge Propagation Through Social Organisations. In Between school and work: New perspectives on transfer and boundary-crossing, edited by T. Tuomi-Gröhn and Y. Engeström. Amsterdam/Oxford: Pergamon.

Becker, J. R. (1995). Women's ways of knowing in mathematics. In G. Kaiser \& P. Rogers (Eds.), Equity in mathematics education: Influences of feminism and culture (pp. 163174). London: Falmer.

Black, L. (2004a). Differential participation in whole-class discussions and the construction of marginalised identities. Journal of Educational Enquiry, 5(1), 34-54.

Black, L. (2004b). Teacher-pupil talk in whole-class discussions and processes of social positioning within the primary school classroom. Language and Education, 18(5), 347-360.

Black, L. \& Williams, J. (2013) Contradiction and conflict between 'leading identities': becoming an engineer versus becoming a 'good Muslim' woman. Educational Studies in Mathematics 84 (1), 1-14.

Black, L., Williams, J., Hernandez-Martines, P., Davis , P and Wake, G. (2010) Developing a 'Leading Identity': The relationship between students' mathematical identities and their career and higher education aspirations. Educational Studies in Mathematics 73 (1), 55-72

Boaler, J. (2002). Experiencing school mathematics: Traditional and reform approaches to teaching and their impact on student learning. Lawrence Erlbaum Associates: Mahwah, New Jersey.

Boaler, J., \& Greeno, J. G. (2000). Identity, agency, and knowing in mathematics worlds. In J. Boaler (Ed.), Multiple perspectives on mathematics teaching and learning (pp. 171-200). Westport, CT: Alex.

DfE (2013) First statistical release available from https://www.gov.uk/government/uploads/system/uploads/attachment_data/file/251184 ISFR40_2013_FINALv2.pdf accessed 30.6.14

Forgasz, H., Becker, J. R., Lee, K.-H., \& Steinthorsdottir, O. (Eds.). (2010). International perspectives on gender and mathematics education. Charlotte, NC: Information Age.

Forgasz, H. \& Rivera, F. (eds) (2012). Towards equity in mathematics education: Gender, culture, and diversity Dordrecht: Springer.

Gutierrez, K. (2008). Developing a Socio-critical Literacy in the Third Space. Reading Research Quarterly, 43(2) pp. 148-164. 
Guitierrez, K., Baquedano-Lopez, P., \& Tajeda, C. (1999). Re-thinking diversity: Hybridity and hybrid language practices in the third space. Mind, Culture and Activity, 6(4), 286-303.

Gutiérrez, R., \& Gutierrez, R. (2013). The sociopolitical turn in mathematics education. Journal for Research in Mathematics Education, 44(1), 37-68.

Gutstein, E. (2006). Reading and writing the world with mathematics: Toward a pedagogy for social justice. New York: Routledge.

Hall, J. (2010). The influence of high school and university experiences on women's pursuit of undergraduate mathematics degrees in Canada. In H. Forgasz, J. R. Becker, K.-H. Lee, \& O. Steinthorsdottir (Eds.), International perspectives on gender and mathematics education (pp. 365-389). Charlotte, NC: Information Age: Information Agex.

Holland, D., \& Lachicotte, W. (2007). Vygotsky, Mead and the new sociocultural studies of identity. In H. 582 Daniels, M. Cole, \& J. Wertsch (Eds.), The Cambridge companion to Vygotsky (pp. 101-135). Cambridge: Cambridge University Press.

Holland, D., Lachicotte Jr, W., Skinner, D., \& Cain, C. (1998). Identity and agency in cultural worlds. Cambridge, Massachusetts: Harvard University Press.

Joint Council for Qualifications (2013) Entry trends, gender and regional charts GCE 2013, available from http://www.jcq.org.uk/media-centre/news-releases/entry-trendsgender-regional-charts-gce-2013, accessed 31.10.14

Kaiser, G., Rogers, P. (1995) Introduction: Equity in Mathematics Education. In Rogers, P., \& Kaiser, G. (eds). Equity in mathematics education: Influences of feminism and culture. Routledge.

Leont'ev, A. N. (1978). Activity, consciousness, and personality. Englewood Cliffs, N.J.: Prentice-Hall.

Leont'ev, A. N. (1981). The development of mind. online version: Psychology and Marxism Internet Archive: www.marxists.org/archive/leontev/works/development-mind.pdf

London Mathematical Society (2013) Advancing women in mathematics: Good practice in UK university departments, available from http://www.blitzadv.co.uk/LMS-BTL17Report.pdf accessed 30.6.14

Mendick, H. (2005). A beautiful myth? The gendering of being/doing 'good at maths' Gender and Education, 17( 2), 203-219.

Mendick, H., Moreau, M.-P. \& Hollingworth, S. (2008). Mathematical images and gender identities. Report for UK resource centre for women in science, engineering and technology (UKRC).

Pais, A. (2014). Economy: the absent centre of mathematics education. ZDM The International Journal on Mathematics Education 46:1085-1093

Rodd, M., \& Bartholomew, H. (2006). Invisible and special: young women's experiences as undergraduate mathematics students. Gender and Education, 18(1), 35-50.

Solomon, Y. (2007). Not belonging? What makes a functional learner identity in the undergraduate mathematics community of practice? Studies in Higher Education, 32(1), 79-96.

Solomon, Y. (2012). Finding a voice? Narrating the female self in mathematics. Educational 
Studies in Mathematics 80 1-2, pp. 171-183

Stetsenko, A., \& Arievitch, I. M. (2004). The self in Cultural-Historical Activity Theory: Reclaiming the unity of social and individual dimensions of human development. Theory and Psychology, 14(4), 475-503.

Skovsmose, O. \& Greer, B. (eds) (2012). Opening the cage: Critique and politics of mathematics education Sense Publishers.

Vygotsky, L.S. (1978). Mind in society: The development of higher psychological processes. Ed. M. Cole et al. Cambridge, Mass.: Harvard University Press.

Walls, F. (2009). Mathematical subjects: Children talk about their mathematics lives. Dordrecht: Springer.

WISE (2012) Women in science, technology, engineering and mathematics: From classroom to boardroom, available from

http://www.wisecampaign.org.uk/files/useruploads/files/wise_stats_document_final.p df, accessed 30.6.14. 